\title{
E-government Evaluation and Organizational Learning
}

\author{
Aini Aman \\ School of Accounting \\ Universiti Kebangsaan Malaysia \\ Malaysia
}

\author{
Hasmiah Kasimin \\ School of Economics \\ Universiti Kebangsaan Malaysia \\ Malaysia
}

\begin{abstract}
Most evaluation processes in e-government projects are neglected, inefficient or ineffective and tend to focus on narrow aspect of project design and implementation. E-government evaluation should support organizational learning in order to ensure that errors or mistakes on previous project are not repeated. This paper presents issues of evaluation in one of e-government project; e-procurement. Using a case study approach of e-procurement project in Malaysia government, interviews were conducted in eight ministries and the developer's company between 2008 and 2009. The finding suggests evaluation practice and use to support organizational learning along the system development life cycle. This paper provides empirical evidence to enhance understanding on both evaluation practice and use that support organizational learning in e-procurement project of Malaysia government.
\end{abstract}

Keywords: E-government, E-procurement, Malaysia, Evaluation, Learning

\section{Introduction}

E-Government means the use of information technology (IT) to enhance the access to and delivery of government services to benefit citizens, business partners and employees [19]. Most evaluation processes in e-government projects are neglected, inefficient or ineffective due to many difficulties encountered in measuring the benefits and costs of such systems [13]. Evaluation of e-government project shows that reported that e-government failure rates of between $20 \%$ and $25 \%$ and only $16 \%$ of Information Technology (IT) projects were considered successful [10].

Evaluation is a business process that should encompass both explicit and tacit assessment such as complex social and material issues of the project investment ([12] and [13]) and organizational learning. Cost Benefit Analysis (CBA) and Net Present Value (NPV) and Return on Investment (ROI) are some of the techniques that managers choose from when appraising IT investments ([12], [15]). E-government evaluation needs to encompass both explicit and tacit assessment such as complex social and material issues as well as technological elements [11].

Organizational learning is necessary to cope with rapid and unexpected changes such as in egovernment project. It requires evaluation to provide with necessary feedback. Government staffs often had difficulty to learn from failures [10]. Steps that can improve the use of e-government evaluation report for learning include identify the needs of users' report and prepare interactive and current report [15].

Although learning to use new methods, techniques and measurement criteria is regarded as necessary but it is limited. Studies to date have only concentrated on evaluation of e-government stages of growth [7], evaluation of electronic service delivery via the internet and web-site ([7], [4]), evaluation of stakeholder involvement including echampion and e-government hybrids ([6], [9]) and evaluation of the costs and benefits of e-government ([2], [3]).

Hence, the aim of this study is to understand the evaluation practice and evaluation use that support organizational learning. The aim of this paper is to provide empirical evidence to the idea of egovernment evaluation and organizational learning [16]. This paper addresses specific questions; (1) what are the evaluation practice and evaluation use in e-government project and (2) how do both evaluation practice and evaluation use can provide support in organizational learning. Using a case study of e-procurement, which is one of the egovernment, project in Malaysia, this paper provides understanding on the evaluation practice and evaluation use that can support organizational learning in e-government project.

This paper proceeds as follows. Next section presents the theoretical framework of this study. Later, methodology section provides methodology and background of e-procurement project in Malaysia government. Then, findings and discussion section explains the evaluation practices and how they are used for decision making and learning. This paper ends with conclusion and implications section. 


\section{Theoretical Framework}

Our theoretical framework draws on [16] that propose a conceptual framework to understand egovernment evaluation that supports learning. The framework makes use of system life cycle, organizational learning and knowledge management. The development of the framework draws literatures in evaluation practices and evaluation use ([15], [19]) and organizational learning theory ([1] and [8]).The framework (Figure 1) consists of two parts: evaluation practices and evaluation use that support learning.

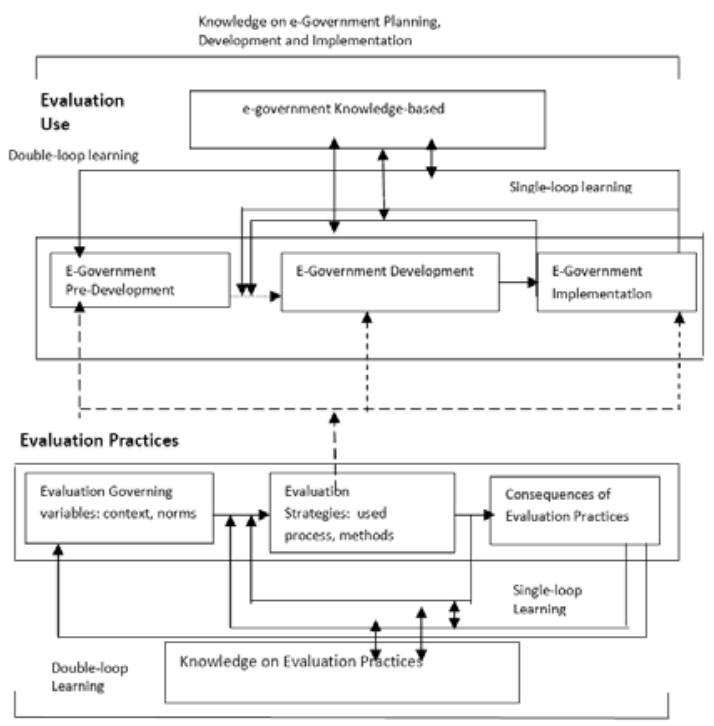

Figure 1. Evaluation that support learning

\subsection{E-government Evaluation Practice}

E-Government evaluation practices refer to the general policy in the company with respect to evaluation instructions, procedures, criteria, methods and techniques, and responsibilities determined for egovernment investments [15]. The evaluation policy can range from subjective arguments made by experts to binding and written evaluation instructions specifically designed for system investments. Evaluation practices emphasize on the need for learning based on knowledge on existing concepts, methods, techniques and related evaluation criteria. The choice of relevant methods and techniques to be used in evaluation is depending upon previous learning experiences. The process of developing knowledge on evaluation practices includes concept, methods and techniques on evaluation [19]. In the case of e-government, knowledge management is important to support learning on evaluation practices. Evaluation practitioners need help to choose relevant methods and techniques in practical situation and get access to previous experiences.

\subsection{E-government Evaluation Use}

Evaluation use or utilization means going beyond the evaluation report by using the information in the report to make decision. Evaluation use means using the information in the evaluation report to make decision. The evaluation does not end when the report of the evaluation result is obtained, but end when a decision is made because of the value obtained [14]. For example, evaluation practice is usually in the form of project proposal appraisal or cost benefit analysis study as part of feasibility study. The results of the evaluation practice are used for developing goal and strategy to develop or improve a system. Only effective evaluation practices ensure genuine results [14], while poor evaluation procedures may leads to a number of difficulties such as to select projects for investment, to control development and to measure business return after implementation [5].

\subsection{Organizational Learning}

Organizational learning here refers to the use of organizational memory, knowledge storage or documentation and feedback loop ([1], [8]). Both studies suggest the use of single loop learning, double-loop learning and deutro learning.

For evaluation practice, single-loop learning is learning to improve existing used of evaluation methods and techniques. Double-loop learning is learning on new methods and techniques that are relevant to new needs. In the context of evaluating information systems, double-loop learning means that problem coping knowledge and conditional knowledge stores are maintained to improve future evaluation. Deutro-learning is developing feedback to support the single-loop and double-loop learning to occur.

For evaluation use, single-loop learning means that organizational memory is used to improve egovernment implementation to achieve goals and objectives according to norms, strategies and assumptions of the project announced by the organization. Single-loop learning refers to changes during development stage. Double-loop learning refers to the changes that involve assumptions and goals of the project. It means that problems relating to the projects are stored and maintained to improve future e-government projects, for example, redefining the service delivery methods. Deutro learning means that there is also feedback loop to the organizational arrangements that allow changes in the governance structures of the e-government project implementation.

The framework is developed as part of our bigger studies in which surveys and case studies were conducted among users in several e-government 
projects in Malaysia. The framework suggests that egovernment evaluation should relate learning to both aspects of evaluation practices and evaluation use to support learning on e-government. The proposed framework is useful to identify evaluation practices and evaluation use that support learning but lack of empirical evidence. The usefulness of the proposed framework needs to be validated in case studies of egovernment evaluation. Further development of the components of the framework which give guidance on how to assess aspects of evaluation use and evaluation practices will make the framework more useful. This paper will present the empirical evidences using a case study of e-procurement project and provides understanding on the evaluation practice and evaluation use that can support organizational learning. The above explanation can be summarized as in Table 2 .

Table 1. Summary of Theoretical Framework

\begin{tabular}{|l|l|l|}
\hline & Evaluation Practices & Evaluation Use \\
\hline $\begin{array}{l}\text { E-government } \\
\text { Evaluation }\end{array}$ & $\begin{array}{l}\text { The general policy in } \\
\text { the company with } \\
\text { respect to evaluation } \\
\text { instructions, } \\
\text { procedures, criteria, } \\
\text { methods and } \\
\text { techniques, and } \\
\text { responsibilities } \\
\text { determined for e- } \\
\text { government } \\
\text { investments. }\end{array}$ & $\begin{array}{l}\text { Use the information } \\
\text { in the evaluation } \\
\text { report to make } \\
\text { decision. }\end{array}$ \\
\hline $\begin{array}{l}\text { Organizational } \\
\text { Learning }\end{array}$ & $\begin{array}{l}\text { The need for learning } \\
\text { based on knowledge on } \\
\text { existing concepts, } \\
\text { methods, techniques } \\
\text { and related evaluation } \\
\text { criteria. }\end{array}$ & $\begin{array}{l}\text { The need for } \\
\text { learning about the } \\
\text { system based on } \\
\text { evaluation results to } \\
\text { improve the system } \\
\text { by changing the } \\
\text { system's strategies } \\
\text { and/or by changing } \\
\text { assumptions and } \\
\text { goals related to the } \\
\text { system }\end{array}$ \\
& & \\
\hline
\end{tabular}

\section{Methodology}

This study adopts a qualitative research design with an interpretive case study approach [21] to allow in-depth understanding of the evaluation practices and uses that support learning. The case study consists of eight government ministries and the developer involved in the e-procurement systems. All eight government ministries have implemented at least one module of e-procurement such as direct purchase.

\subsection{E-Procurement Project Background}

The Government of Malaysia launched egovernment as one of the Multimedia Super Corridor (MSC) Flagship Applications with the aspiration to employ multimedia technologies to re-invent the way the government operates. One of the applications is e-procurement project known as e-Perolehan (eP). The eP streamlines government procurement activities and improves the quality of service it provides and converts traditional manual procurement processes in the Government machinery to electronic procurement on the Internet.

The Government has appointed a third party vendor called CommerceDotCom Sdn. Bhd. (CDC) in year 1999 to develop, operate and execute the eP project based on Build-Operate-Transfer (BOT) basis. The eight years contract has been extended for an extra five years untill April 2012. CDC developed eP systems modules named Central Contract, Direct Purchase, Quotation, Tender and Electronic Reverse Auction (ERA) or eBidding. All Suppliers are required to be registered with the Ministry of Finance (MOF) Malaysia and eP enabled (fully equipped with IT infrastructure and training on product usage) before transacting with the Federal Government of Malaysia. The full enablement requirements covers full set of computer with internet line connection, eP access medium, and training to use eP system.

The scope of work and implementation schedule for eP was carried out in four phases. The first phase of the eP initiative started in October 2000, with the intention of developing an eP system for the purchase of goods involving responsibility centers within the government. The second phase of the project started in January 2001 to expand eP system to one responsibility center of the ministries. The idea was to develop eP system for purchases through tender, quotation and direct purchase for all agencies involved. Phase three of the eP project started in January 2002. The focus of this phase was to roll-out the systems developed in Phase 1 and 2 and to get the various entities involved in the initiative into an execution mode. Phase four started in January 2004, with the objective of improving eP system accordingly, based on feedback received from all three parties involved in the procurement process; the service provider, the buyer community and the various responsibility centers' within the government sector. Since the year 2000 until 30th June 2007, $53 \%$ which is 1,419 out of 2,679 of government agencies have been identified (having a complete data) as eP enabled and it is expected all government agencies would be eP enabled by the end of 2009 . 


\subsection{Data Collection}

Data collections include semi-structured interviews, document reviews and observation. Interviews involved 18 individuals with 28 hours interviews. Details of interviews are shown in table I. All interviewees are engaged, to varying degrees, with the deployment of e-procurement system including Head of Technical Division, Head of Policy and Implementation, Chief Secretary, Assistant Secretary Finance Division, Account, Director, Secretary Member of Finance Division (Eprocurement Unit), Head Secretary of Finance and Account, Assistant Secretary of E-procurement Unit, Assistant of IT Officer , Senior Assistant Admin Officer, Assistant Secretary of E-Procurement Division, Assistant Secretary of E-Procurement and Management Division and Assistant Secretary. The interviewees were questioned on their understanding of the e-procurement system, organization structure and responsibilities, implementation process, system procedures and control as well as evaluation practices in e-procurement project at each stage of system life cycle.

Table 2. Summary of Interviews

\begin{tabular}{|l|l|}
\hline & Hours \\
\hline Ministry & 4 \\
Ministry of Finance & 2 \\
MAMPU & 4 \\
Ministry of Works & 2 \\
Prime Minister's Department & 3 \\
Ministry of Domestic Trade and Consumer Affairs & 2 \\
Ministry of Health & 3 \\
Ministry of Human Resource & 2 \\
Ministry of Agriculture and Agro-based Industry & 3 \\
Ministry of Education & 3 \\
CommerceDotCom Sdn Bhd & 28 \\
\hline Total Hours & \\
\hline
\end{tabular}

\subsection{Data Analysis}

Interviews were taped and transcribed. Coding of transcripts was undertaken by researchers independently and then cross-checked for final coding. Data analysis involves identification of issues and development of themes from the transcripts, notes and documents. Researchers later review literatures to identify appropriate theoretical framework to explain the themes. Hence, the theoretical framework is not a priori. The researcher makes sense of the data using the theoretical framework and explains the findings accordingly.

\section{Analysis of Findings}

This section will explain our findings in understanding evaluation use and evaluation practice that support learning throughout each stage of system development, starting from pre-development stage, follows with development stage and postdevelopment stage.

\subsection{Pre-Development Stage}

In the pre-development stage of e-government, the method used in evaluation include e-government blue-print and e-government information technology standard, government circular for ICT project, concept of request for Proposal (CRFP), and technical and financial tender evaluation report.

The planning process for e-government project started in 1996. There were voluntary web shapers from twenty different agencies who were stationed at MAMPU for three months. The web shapers' role includes identifying the best practices in egovernment and performing feasibility studies for the e-government project. According to the Director:

"The web shapers looked at the best practices around the world and understand how they started egovernment project, and type of applications being focused on. We also looked at people, software and other technology facilities that were available at that time. In addition to that, we had to make sure that the application follows system, procedures and any related government acts. Planning took about three to four months where at the end of the period, they produced E-government Blueprint and E-government Information Technology Standard or EGITS”. Director, MAMPU

At the end of the period, they produced Egovernment Blueprint and E-government Information Technology Standard or EGITS. The documents provide guidelines on how to deal or evaluate any e-government project. The learning of best practices around the world had contributed to the development of The Blueprint for e-government implementation that contains explanations on concept, vision, objectives and roadmap of egovernment implementation [20] for future use. For example, in system planning, each government agencies must come out with ICT Strategic Planning (ISP) which is the addition to the public sector ISP which was produced in 2003.

Another evaluation practice is the Government General Circular No. 1 year 2009 that provides guidelines for procurement of ICTs' project by government agencies. According to the circular, any government agencies have to refer to MAMPU for approval of their ICT project.

MAMPU has opened tender for e-government project through Concept Request for Proposals (CFRPs) in year 1997 and officially closed in November 1997. The CRFP is designed to describe the benefits the government is seeking from the eprocurement pilot application. The CRFP is intended to give the flexibility required to innovate the best solutions to deliver the benefits and is used as a basis 
to decide whether or not to award a project to supplier. Specifically, the document contains detail solution requirement such as functional, operational, technical, and financial implication of the project. The technical requirements are kept to a minimum to allow the responding organization room to respond with creative solutions. Additionally the CRFP contains the required capabilities of responding organization such as organizational, financial and technical, general terms and conditions, as well as instructions for the responding organization including procedural timelines.

Evaluation of these CRPs was done in year 1998. Government continues to use the CRFP in future ICT projects that requires vendor to provide information such as what to be developed, what machine to buy or what server capacities required. It is a basis for evaluation and awarding project to vendor. According to one of the senior officer in Ministry of Finance (MOF):

"CRFP for e-procurement was prepared by $M A M P U$ and MDEC that include the evaluation phase and awarding project."

Based on CRFP, MAMPU performed technical and financial evaluation on the tender to get the best technical solution. According to the director in MAMPU,

"We perform technical and financial evaluation on the tender. Of course, we want to find the best technical solution in order to implement the concept what we put up. At the same time, we make sure that the CRFP met mandatory criteria."

They make sure that the CRFP met mandatory criteria such as whether or not it is part of ISP project, and whether or not similar application has been developed by others. Proposals was evaluated by the E-government Steering Committee based on the attractiveness of model for knowledge transfer, acceptance of terms stated in the CRFP, calibre of the responding organization, attractiveness of solution, and involvement with the MSC. One of the officers in MAMPU told us:

"For financial evaluation, few things that we look at as mandatory criteria such as whether or not it is part of ISP project as the ISP must be supporting the business strategic planning. We check whether or not there is similar application being developed by others. If there is, we ask them to share and use the concept of sharing or smart partnership. If not, we look at other criteria; whether or not they can support their request and being approved or during the process, they found out that the project is not good for them. Based on its budget, MAMPU will evaluate all the requests and suggest the amount allocated to that project. For example, if we estimate this project to be RM100 million and we found that the scope of work is too big, we will give our comment."
According to one of the director in MAMPU, each technical and financial evaluation will produce report for judgment and approval of Procurement Committee. Decision made will be entire based on the report. In the tender board meeting, the chair and the technical committee member will be there. The agencies will be called in when required. When they were called in, there must be something quite not right with the documentation and need more explanation. They have to answer. Sometimes, they were called in to help the board made a right decision. Sometime they just want to meet them face-to-face. In planning for example, the decision will either be accept or reject the tender. The difficult part in making decision is when the tender form, or specification are not well prepared, the evaluation will become more difficult.

The process is well written in one of government circulars, thus helps future evaluation process of tender. When MAMPU receive tender, the circular guides them on how to do the evaluation such as the type of set-up that vendor need to prepare, who should be in the technical and financial evaluation committee and what they need to do. According to one of the officers in MAMPU,

"When I was in the Procurement Committee before, I could see whether or not they follow procedures. If they didn't follow the procedures, technically, we can disqualify their evaluation and ask them to redo. The report that need to be produced is standardized and common which can be applied in any ministries. Even when I went to other ministries, I followed the same procedures and came to conclusion. There will be three reports. The first report contained recommendation and was prepared by the committee, the second report was from technical committee and the third was from the tender board that will use that document for individual assessment."

Every report or documents that were produced were kept in internal network. The staffs who worked on the project will have access to the document and get information about the past evaluation report. Only staff with access right can access the document to protect its privacy. Only those who require that report to make decision will be allowed to access the documents.

\subsection{Development Stage}

In the development stage, evaluation process involves ministries, government agencies and responsibility centers. Findings indicate the use of Proof of Concepts (POC) and feedback report in the evaluation process at each phase of eP development.

Proof of Concept (POC) refers to a partial solution that involves a relatively small number of users acting in business roles to establish whether the system satisfies some aspect of the requirements. 
The evaluation of POC involved CDC, technical and management staffs. POC was required at each phases to ensure the successful of eP implementation.

Since the system was developed based on prototyping and use Build Operate Transfer (BOT) approach, preparing POC requires the involvement of CDC, technical and management staffs. Proof of Concept (POC) refers to a partial solution that involves a relatively small number of users acting in business roles to establish whether the system satisfies some aspect of the requirements. It is usually considered a milestone on the way to a fully functioning prototype. For eP, POC is required before further development is allowed. The objective of evaluation at each phases was to ensure that it can be implemented. As one of the officers in MOF explain:

"BOT is more special because vendor will have to make sure that the system is really working and being used widely in order to earn profit. Everyone from every level in technical elements and system development were involved in the preparation of POC evaluation report before it was sent to Director. There was a meeting at the ealier stage among technical and management people. All were involved accept the clerk. There were 12 person involved in each meeting. The technical people will check the functionality, every phase and later, the Chief Deputy Director with other management team will report to the management."

Documents such as Business Process Design (BPD), Technical Specification Requirement (TSR), Disaster Recovery Center (DRC) and the Transfer of Technology (TOT) were required to support the POC evaluation. For example, in the first phase, CDC delivered the contract module and vendor registration module and before $\mathrm{CD}$ was allowed to proceed to the second phase the scope of work and functionality, deliverables and documents such as BPD and TSR need to be submitted at least three months earlier. The first phase had completed the POC. However, the POC of the second stage was conditional because the DRC and TOT were not completed.

According to the officer, the vendor needs to meet users expectation before the vendor develop the system. The vendor developed prototype and implement the system by phases to ensure that the system meet the expectation of small number of users by which they will improve the system from a small scale users expectation. Learning from mistakes and improving it before full implementation accross ministries will ensure a successful eP system. He added:

"It will more accurate if what we want is available. For example, what is the specification that we agreed? Before they develop the system, they produce $B P D$ which we will read first before giving confirmation. They develop prototype first before develop the system."

The officer further explained that they highly relied on informal continuous evaluation such as feedback and report to ensure that the system is usable. A senior officer in MOF commented that they learned and improved the system from the feedback received from users. Every comment would be included in the report and presented in the meeting. A Standard Operation Manual (SOP) is followed to ensure that each comments and feedbacks were properly documented and included in the report. She explained:

"We improve the system based on feedback. New suggestions from coordinator officers in the ministry will be included in the report for technical meeting. In order to overcome issues in e-procurement implementation, government provides SOP manual and documented all the issues properly."

Ministry of Finance is responsible to perform evaluation at each ministry using feedback method. The implementation agency will report to the Chief Secretary who will then report to the Ministry of Finance for further action mainly to improve the system. Findings show that the evaluation method being used include three meetings a year to discuss and report issues related to e-procurement. The purpose is to ensure that the system work and function as expected. Under each department or ministries, an implementation committee was established. They will work together with CDC to perform system evaluation. The evaluations were performed at each stage of planning, development and implementation of the system. He says;

"System evaluation for $\mathrm{eP}$ has been performed at each level of system planning, development and implementation. Normally, evaluation is performed at each Ministry through meeting. Ministry of Finance is responsible to perform evaluation at each ministry using feedback method. Then, the implementation agency will report to the Chief Secretary who will then report to the Ministry of Finance for further action."

The officer in MOF explains that he will use the report for monitoring purposes that is to ensure that the transactions can be done without difficulties faced by users or vendors.

"The purpose of evaluation system is to ensure that the system that cost millions work efficient and effective and to ensure the transactions can be done without difficulties faced by users or vendors."

The officer also explained that although a team has been set up to develop the system, there are individuals to ensure the effectiveness of the system implementation. These individuals have responsibilities to ensure that technical problems in users' department are being referred to the centre department. If the problem cannot be solved by the eP's representative of the user's department, the 
issues have to be discussed in the meeting at centre level. This is to ensure that each event that happened can be traced by the centre department indirectly and appropriate action can be done.

\subsection{Post-Development Stage}

In the post-development stage, the evaluation practice includes the use of report on transaction and Return on Investment (ROI).

Each ministry had to submit transaction report for each department ministry twice yearly. A report on eP usage from government agencies and responsibility centers has to be presented in the ministry meeting. The Procurement Unit of MOF also prepares Annual Work Assessment Report that contains evaluation on the management of procurement and eP system. One of the officers in Prime Minister Office told us:

"A report on the usage of the $e P$ system from government agencies, responsibility centers and ministries as well as CDC will prepare report and present in the ministry meeting. These include complain, difficulties and ways of improving its system."

In order to ensure that all ministries use e-P, MOF release a circular that required each ministry to use $\mathrm{eP}$ and the performance evaluation of each department will take into consideration their level of eP transactions. The Director of CDC explained:

" $1 \%$ or $5 \%$ of their performance evaluation are based on their usage level of $e P$. If the ministries did not use eP, they lost the 5\% marks. The number of transactions is increasing especially after the circular enforcing all ministries to use $e$ procurement."

The evaluation on each ministries implementation of e-procurement was based on star rating. The ministry that had the highest rating was considered the most successful ministry implementing the system. The star rating was based on the report of number of transactions in each ministry.

Another evaluation practice that is used is Return on investment (ROI). ROI is used to determine the renewal or extension of contract of CDC. The extension of the contract is important to CDC as it has not yet recovered the cost of developing eP system. According to the CDC Director:

"I've spent RM250 million since 2002 until now (2009). The contract was extended to 2012 to make sure we get our return. Now, we have not even reached breakeven. We took a loan of RM100 million and we had paid the RM35 million. That was only interest. We have to recover the cost. I've explained this to the government and they allowed extension."

Since the BOT system required CDC to cover the cost of eP project, CDC is allowed to collect $0.8 \%$ per transactions with maximum ceiling of RM9600 per eP transaction. For example, if the transactions value is RM5 million, they should get at least RM40,000 ( 0.8\% x RM5 million), but they will not get RM40,000. They will only get RM9,600 because of the maximum ceiling. In order to ensure the ROI, CDC has to ensure that the number of users and transactions is increasing. The director added:

"This system is built based on Built Operate Transfer (BOT) concept and I am the interested party. I love my customer and make sure that they can use my system. I have to make sure that the system works well at all time. If not, I'll upgrade the system to make it work or else I won't be able to get that $0.08 \%$ commission."

The evaluation practices used in this relied heavily on the report of number of transactions and ROI. Based on the reports, CDC and government can determine actions to be taken in order to ensure successful implementation of e-procurement system. For example, mandatory handholding was initiated to train government users and suppliers. The Director of CDC explains:

"I have to send my staffs to the users' sites to ensure that the implementation of eP is successful. The staffs will explain, persuade and train the users as well as solve problems. These Mandatory Handholdings are being used extensively to ensure that the users are able to use eP. CDC allocates 60 technical staffs at each of ministry and responsibility centre for assistance. The technical staff will be there until they are sure that the eP have been fully implemented. CDC spent about RM120 000 per month for the technical staffs to claim on transport and travelling cost. The same method is being applied to suppliers.”

\section{Discussions and Conclusion}

This paper has presented preliminary findings on the evaluation practice, evaluation use and organizational learning using a case study of eP implementation in Malaysian e-government project. The theoretical framework [16] assists in answering the research questions presented earlier; (1) what are the evaluation practice and evaluation use in egovernment project and (2) how do both evaluation practice and evaluation use can provide support in organizational learning. The findings provide empirical evidence that there are reports or documents that were used as evaluation practice for particular evaluation use.

During the pre-development stage, E-government Blue-print, E-government Information Technology Standard (EGITS) and Government Circular for ICT Project provide guideline on how to deal with egovernment project and were used for approval of egovernment project. Concept of Request for Proposal (CRFP) provides information to vendor about ICT or system requirements to be developed and was used for decision to award project to vendor/supplier. 
Technical and Financial Tender Evaluation Report provide guidelines for tender evaluation and was used to decide on the best solution for ICT project technically and financially.

During the development stage, Proof of Concepts (POC) was used to decide whether or not should continue to next phase and a feedback report was used to improve the system. In the post-development stage, evaluation practice include the use of report on usage of eP to determine the award of 'star' rating, Service and Return on Investment (ROI) to determine renewal or extension of contract and training required for users and suppliers.

There are also some evidence of evaluation practices and evaluation use that support learning. For example, during the development stage, the ministries highly relied on informal continuous evaluation such as feedback and report to ensure that the system can be fully used. Suggestions or issues from the feedback and report from meetings were documented properly. These may allow knowledgebased repository for future improvement in eP and changes in terms of system's objectives, users' requirements and evaluation practices. Feedback information from development and implementation process is necessary to support decisions in improving the system.

Theoretically, this paper enhances the ideas of evaluation practice and evaluation use that support learning [16] by providing empirical evidence using eP case in Malaysia e-government. This study enriches the literatures ([15], [19]) that focused on evaluation of e-government evaluation practice and use for organizational learning.

Practically, this study suggests the use of BOT approach for any e-government project. With BOT, developers will be more obligated to ensure that the system performed as required. Indirectly, the government transferred the responsibility of system evaluation to the vendor. Evaluation practices require documentation, reports and guidelines to allow organizational learning. Evaluation can provide feedback information on IS development and implementation. Feedback is necessary to support decisions in improving the system.

By understanding the evaluation practices and evaluation in e-government project, this paper provides a basis for further thought and analysis of evaluation and the organizational learning. For example, the informal feedback, documentation and reporting are found to be significant in the evaluation process, hence requires further study and analysis.

\section{Acknowledgement}

This study was financed by Research Grant University (UKM-GUP-TMK-08-01-303) and Fundamental Research Grant Scheme (UKM-EP-05FRGS0054-2009).

\section{References}

[1] Argyris, C., and Schon, D. (1978) Organizational learning: A theory of action perspective. Reading, Mass: Addison Wesley

[2] Bannister, F. (2002) "Sustained delivery of value: the role of leadership in long-term IS effectiveness," Evaluation and Program Planning, Vol. 25, No. 2, pp. 151-158.

[3] Bannister, F. and Remenyi, D. (2003) "The societal value of ICT: first steps towards an evaluation framework", Electronic Journal of Information Systems Evaluation, Vol. 6 No. 2 pp. 197-206

[4] Beynon-Davies, P. and Williams, D. (2003) "Evaluating electronic local government in the UK", Journal of Information Technology, No. 18, pp 137-149.

[5] Farbey, B., Land, F., Targett, D.(1999) Moving IS evaluation forward: learning themes and research issue”, Journal of Strategic Information Systems 8,pp 189-207.

[6] Foster, A. and Griffin, D. (2003) "The Local Authority e-Champion: The Hybrid Manager Needed to Make Joined-up e-Government a Reality?" in Proceedings of the 3rd European Conference on e-Government, D. Remenyi and F. Bannister (Eds.), Dublin.

[7] Griffin, D. and Halpin, E. (2002) "Local Government: a digital intermediary for the Information Age?", Information Polity, Vol 7 No. 4, pp. 217-231.

[8] Hallikainen, P. (1999) "Improving the Success of Information Systems by Evaluation A Learning Approach”, Publications of Helsinki School of Economics and Business Administration, Research Report W-228.

[9] Heeks, R. (2002) "e-Government in Africa: promise and practice”, Information Polity, Vol 7 No. 2/3, pp 93114.

[10] Heeks, R. (2008) Success and Failure in Egovernment Projects. http://www.egov4dev.org/success/. (Access date: 8 August 2008)

[11] Irani Z,, Love P. E. D. and Jones, S. (2008) Learning lessons from evaluating eGovernment: Reflective case experiences that support transformational government, The Journal of Strategic Information Systems, v.17 n.2, p.155164, June.

[12] Irani, Z. (2002) "Information systems evaluation: navigating through the problem domain", Information \& Management, Vol 40, pp 11-24.

[13] Irani, Z., and Love, P.E.D. (2001) EditorialInformation Systems Evaluation: Past, Present, and Future, European Journal of Information Systems, Vol.10, pp. 183-188.

[14] Juristo, N. (1997) "Structuring the Knowledge-Based Systems Evaluation Process", Intelligent Information Systems, IIS '97 Proceedings. 
[15] Jones, S. Irani, Z. and Sharif, A. (2006) EGovernment Evaluation: Reflections on Three Organizational Case Studies, Proceedings of the 40th Hawaii International Conference on System Sciences.

[16] Kasimin, H., Sahari, N., Zulridah Mohd-Noor, Z., Yahya, Y., and Aman, A. (2009). Towards an Interpretive Framework for e-Government Applications Evaluation in a Developing Country That Support Learning, Proceedings of The 9th European Conference on e-Government, pp371380.

[17] Layne, K. and Lee, J. (2002) "Developing fully functional e-government: a four stage model”, Government Information Quarterly, Vol 18 pp 122-136.

[18] Oh, C.H. and Myeong, S. (2002) Evaluationg EGovernment: A Lesson from Korea, International Review of Public administration, Vol.7, No. 2, pp. 33-43.

[19] Orange, G., Burke, A., Elliman, T., and Kor, A., (2006) CARE: An Integrated Framework to Support Continuous, Adaptable, Reflective Evaluation of Egovernment Systems, European and Mediterranean Conference on Information Systems (EMCIS).

[20] Othman, R. and Rahmat, A. R. (2006) "The analysis of e-government blueprint for implementation towards the e-government actual implementation," The Proceedings of Knowledge Management Conference and Exhibition (KMICE 2006).

[21] Walsham, G. (1995) Interpretive case studies in IS research: nature and method. European Journal of Information Systems. 4(2), 74-81. 